\title{
Influence of Water Activity on the Development of Antioxidative Effect during the Maillard Reaction between Histidine and Glucose
}

\author{
Munehiko Tanaka, ${ }^{*}$ Shunji Sugita, ${ }^{*}$ Chiu Wen-Kuei, ${ }^{*}$ \\ Yuji Nagashima,* and Takeshi Taguchi**
}

(Received November 2, 1989)

\begin{abstract}
Influence of water activity on the development of antioxidative effect by the Maillard nonenzymatic browning reaction between histidine and glucose in the presence of microcrystalline cellulose was examined. The formation of brown pigment during the Maillard reaction increased as water activity of the model system decreased and initial rates of color formation reaction at $120^{\circ} \mathrm{C}$ were about twice those at $100^{\circ} \mathrm{C}$ regardless of water activity. Furthermore the initial rate of antioxidative effect development was found to increase with decreasing water activity. Maillard reaction products thus prepared was applied to the production of kamaboko-type sardine product as an antioxidant and the oxidation of sardine lipids was effectively inhibited during storage at $4^{\circ} \mathrm{C}$.
\end{abstract}

The intricate chemical reaction between amino and carbonyl compounds, known as the Maillard browning reaction, has gained increased attention in recent years. The reaction is very common during cooking, processing, and storage of many foods. In most cases, browning is undesirable because of the development of off-flavor and poor color as well as the loss of nutritional value. However, in coffee, baked goods, potato chips, and some other processed foods, controlled browning is indispensable for their desirable characteristics. A considerable amount of researches pertaining to the Maillard reaction have been carried out and reviewed by many workers. ${ }^{1-4}$ )

Polyunsaturated fatty acids in foods are particularly prone to autoxidation. There are a number of examples which indicate that autoxidation plays a crucial role in the formation of off-flavor and toxic substances. The oxidation of fatty acids at first leads to the formation of fatty acid hydroperoxides by a free radical chain reaction. The hydroperoxides subsequently undergo several reactions which bring about the formation of such products as aldehydes, ketones, and other volatile compounds. As a result, rancid flavor is developed and limits the shelf-life of many food products.

The progress of lipid oxidation can be prevented either by adding antioxidants or packaging in vacuum or inert gas. Synthetic antioxidants such as butylated hydroxyanisole (BHA), butylated hydroxytoluene (BHT) and propyl gallate have frequently been used for the processing of foods. However, natural antioxidants are preferred from a food hygienic point of view. In recent years a large number of Maillard reaction products (MRP) were demonstrated to have antioxidative effect and applied as antioxidants to model and food systems. $^{b-8)}$ Despite there being much published work on antioxidative effect on these compounds, no antioxidants formed by the reaction have so far been identified, nor has the mechanism of their antioxidative effect been completely elucidated.

The aims of this work were to study the influence of water activity on the development of antioxidative effect during the Maillard reaction between histidine and glucose and to apply histidineglucose MRP to kamaboko-type sardine products as antioxidants.

\section{Materials and Methods}

\section{Preparation of the Model System}

L-Histidine monohydrochloride monohydrate $(1.25 \mathrm{~g}$, Nihon Rikakagaku Yakuhin Co.) and anhydrous D-glucose $(1.08 \mathrm{~g}$, Kokusan Kagaku Co.) with molar ratio of $1: 1$ were dissolved in $30 \mathrm{ml}$ of $0.1 \mathrm{M}$ phosphate buffer $(\mathrm{pH} 7.0$ ). After $\mathrm{pH}$ value of the solution was adjusted to 9.0 with $20 \% \mathrm{KOH}$, microcrystalline cellulose powder (Avicel, Asahi Kasei Co., $10 \mathrm{~g}$ ) was slurried with

* Department of Food Science and Technology, Tokyo University of Fisheries, Konan, Minato, Tokyo 108, Japan (田中宗彦, 杉田俊二, 邱 文贵, 長島裕二, 田口 武：東京水産大学食品生産学科). 
this solution. The slurry was frozen in a blast freezer $\left(-30^{\circ} \mathrm{C}\right)$ and then freeze-dried. Microcrystalline cellulose is inert to the browning reaction and served as a solid support for the model system. After freeze-drying, samples were crushed with a mortar and pestle to a fine powder and then equilibrated to the desired water activity (Aw) in vacuo over an appropriate saturated salt solutions. For the adjustment of water activity, saturated solutions of $\mathrm{MgCl}_{2}$ (Aw 0.33), $\mathrm{Mg}\left(\mathrm{NO}_{3}\right)_{2}$ (Aw 0.51), and $\mathrm{KCl}$ (Aw 0.84) were employed. The samples were allowed to equilibrate for 3-5 days at room temperature until the proper water activity was obtained. The freeze-dried sample per se had a water activity of 0.15 . Water activity of the sample was checked with a Shibaura AW meter WA-351 (Shibaura Denshi Co.).

\section{Heat Processing}

Samples equilibrated to given water activities were heated at 100 and $120^{\circ} \mathrm{C}$ for up to $70 \mathrm{~min}$. For heating purposes, $1 \mathrm{~g}$ of the sample was placed in a glass vial $(1.0 \mathrm{~cm}$ i.d. $\times 4.2 \mathrm{~cm})$ and sealed with a screw cap to minimize heat transfer limitations in come-up time. At $100^{\circ} \mathrm{C}$ samples were heated in a water bath, and at $120^{\circ} \mathrm{C}$ in a fluidized silica sand bath. At given time intervals, samples were withdrawn and cooled in an ice-water bath.

\section{Determinations of Color and Antioxidative Effect}

The Maillard browning reaction was monitored by measuring brown pigment formation. Brown pigment was extracted by incubating $100 \mathrm{mg}$ of heated sample with $5 \mathrm{~m} l$ of distilled water at $40^{\circ} \mathrm{C}$ for $2 \mathrm{~h}$, followed by centrifugation at $1,000 \mathrm{rpm}$ for $15 \mathrm{~min}$. The development of brown color was determined as absorbance of the supernatant at $420 \mathrm{~nm}$ on a Shimadzu spectrophotometer Model UV-160 after an appropriate dilution. The amount of brown pigment formed was expressed as absorbance at $420 \mathrm{~nm}$ per $\mathrm{g}$ solid.

The apparatus used in this study for the determination of antioxidative effect was similar to that reported by Farr et al. ${ }^{2)}$ Hemin (chlorohemin, Tohyo Kasei Kogyo Co.) was employed as a catalyst for lipid autoxidation. Linoleic acid (200 mg, Tokyo Kasei Kogyo Co.) dissolved in ethanol $(10 \mathrm{~m} l)$ and air-saturated $0.2 \mathrm{M}$ phosphate buffer $(\mathrm{pH} 7.0,14 \mathrm{ml}$ ) was placed in a thermostatically controlled reaction vessel (volume: $25 \mathrm{ml}$, temperature: $\left.25^{\circ} \mathrm{C}\right)$ and MRP solution $(1 \mathrm{ml})$ was added with stirring. Thus, the completely homogeneous solution was prepared without the use of an emulsifier such as Tween-80. The reaction vessel was fitted with an oxygen electrode (Clarktype, Able Co.). To start the autoxidation of linoleic acid, $0.1 \mathrm{ml}$ of $1 \mathrm{~mm}$ hemin in a mixture $(1: 1, \mathrm{w} / \mathrm{w})$ of $0.02 \mathrm{M}$ phosphate buffer $(\mathrm{pH} 7.0)$ and $95 \%$ ethanol was injected. The response of the oxygen electrode was recorded with the aid of an electrometer (Model HE-101A, Hokuto Denko Co.) and a one $\mathrm{mV}$ recorder (Rikadenki Co.). The addition of hemin resulted in rapid decrease in dissolved oxygen content. When antioxidative samples were added to the reaction solution, a longer time was required for the decrease of dissolved oxygen. Therefore, antioxidative effect was calculated as $\mathrm{T}(\mathrm{a}) / \mathrm{T}(\mathrm{c})$, where $\mathrm{T}(\mathrm{a})$ is time elapsed for $50 \%$ reduction of dissolved oxygen in the reaction solution with antioxidative sample, and $T(c)$ is corresponding time interval in the control.

\section{Application of MRP to Kamaboko-type Sardine Product}

Minced sardine Sardinops melanostictus meat (lipid content: $11.5 \%$, moisture content: $68.0 \%$ ) was washed twice with 10 volumes of ice-cold $\mathrm{NaHCO}_{3}$ solution $(0.2 \% \mathrm{w} / \mathrm{v})$ for $10 \mathrm{~min}$. The washed meat was centrifuged and adjusted to a moisture content of $84-85 \%$. Sardine meat thus treated was ground with $2 \%(\mathrm{w} / \mathrm{w}) \mathrm{NaCl}$ and $0,0.5,1.0,2.0,3.0 \%(\mathrm{w} / \mathrm{w})$ MRP powder (Aw $0.15,40 \mathrm{~min}$ heating at $120^{\circ} \mathrm{C}$ ). As references, BHA (Wako Junyaku Kogyo Co.) and L-ascorbic acid (Kokusan Kagaku Co.) were used in the level of $0.095 \%(\mathrm{w} / \mathrm{W})$, respectively. The amount of BHA or ascorbic acid was equivalent to the solid content of MRP added in the level of $0.5 \%$. The meat paste thus prepared was wrapped in polyvinylidene chloride film and heated at $80^{\circ} \mathrm{C}$ for $20 \mathrm{~min}$. After heating, gels formed were cooled in ice-water for $30 \mathrm{~min}$. The kamaboho-type product (called "Tsumire" in Japanese) thus obtained were stored at $4^{\circ} \mathrm{C}$ for up to 13 days. Peroxide value (POV) of lipid extracted with chloroform and methanol mixture (2:1) and thiobarbituric acid (TBA) number of meat were measured at intervals during storage. POV was determined by the iodometric method. ${ }^{10}$ The TBA number was measured according to the procedure reported by Sinnhuber and $\mathrm{Yu}^{11\rangle}$ and expressed as $\mathrm{mg}$ of malonaldehyde per $\mathrm{kg}$ of sample meat. Tristimulus color values of kamaboko-type sardine product were determined by a Digital Color and Color Difference Meter (Model 1010, Nippon Denshoku Kogyo Co.) standardized with a white color tile $(L=90.9, a=0, b=3.1)$. 


\section{Results and Discussion}

\section{Development of Brown Color}

Fig. 1 shows the development of brown color during the Maillard reaction between histidine and glucose as a function of heating time, temperature and water activity. The rate of color development was constant at the initial stage of the reaction and approached a plateau at the later stage, regardless of heating temperature and water activity. The induction period prior to visual detection of an increase in brown color was not observed or at least it was not detected within the accuracy of the determinations used in this study. Data not included here showed more than half of glucose disappeared within $20 \mathrm{~min}$ at $100^{\circ} \mathrm{C}$ and $5 \mathrm{~min}$ at $120^{\circ} \mathrm{C}$ even at $\mathrm{Aw} 0.84$, indicating that the conditions for the Maillard reaction were very favorable.

Initial rates of the brown pigment formation
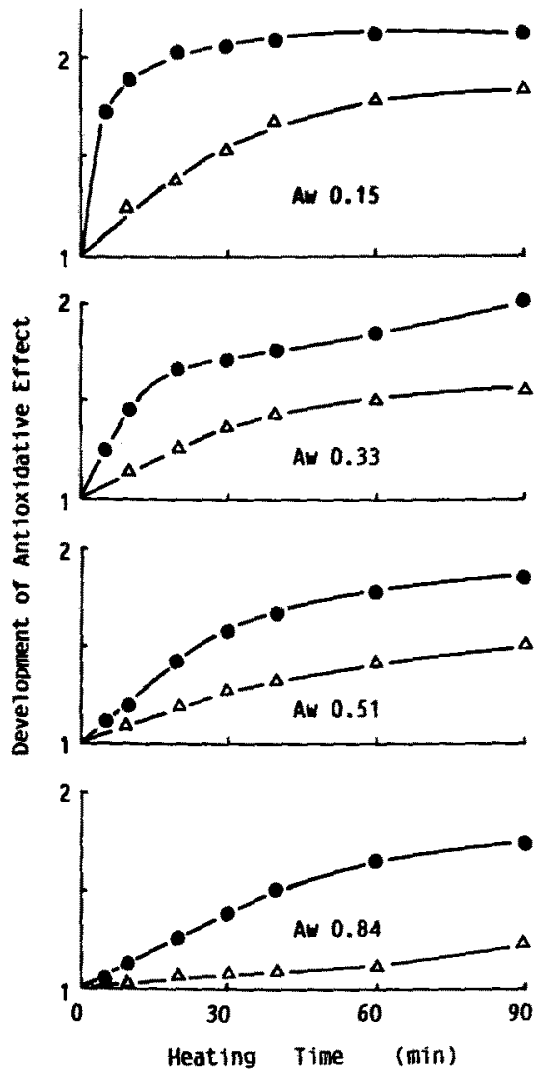

Fig. 1. Effect of water activity, heating temperature and time on the development of color (Abs. at $420 \mathrm{~nm}$ ) during the Maillard reaction between histidine and glucose (molar ratio $1: 1$ ) at $\mathrm{pH} 9$ (20-fold dilution).

$\Delta: 100^{\circ} \mathrm{C}$ heating, $120^{\circ} \mathrm{C}$ heating.

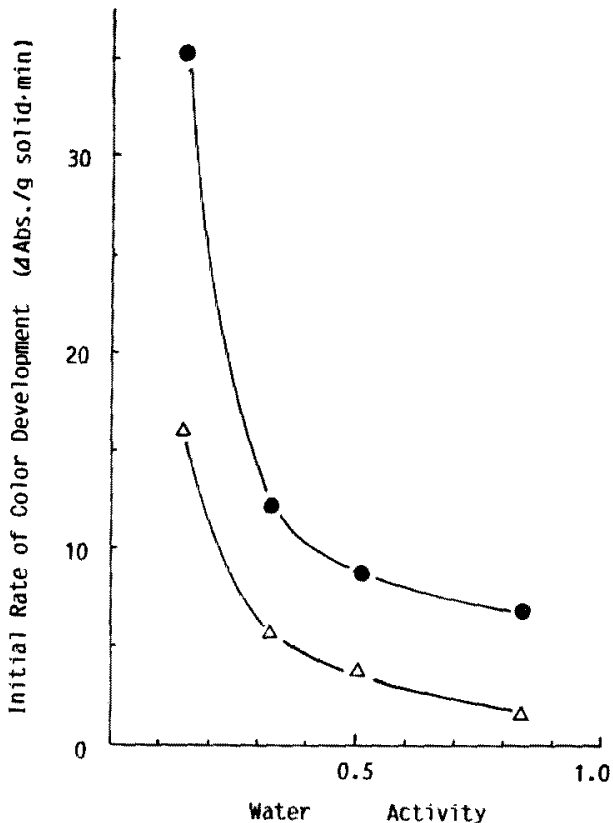

Fig. 2. Relationship between water activity and the initial rate of color development as measured at $420 \mathrm{~nm}$.

$\triangle: 100^{\circ} \mathrm{C}$ heating, $: 120^{\circ} \mathrm{C}$ heating.

( $\triangle \mathrm{Abs} . / \mathrm{g}$ solid $\cdot \mathrm{min}$ ) calculated from slopes of the linear portion of Fig. 1 are plotted against water activity in Fig. 2. The browning rate increased as water activity decreased. This agrees with data reported by Tanaka et al. ${ }^{12)}$ on the Maillard reaction between histamine and glucose, while was not in accord with the results of Warmbier et al. ${ }^{13)}$ which showed a maximum rate around Aw 0.5 . It is noteworthy that initial rates at $120^{\circ} \mathrm{C}$ were approximately twice those at $100^{\circ} \mathrm{C}$ regardless of water activity tested.

\section{Development of Antioxidative Effect}

The development of antioxidative effect during the Maillard reaction between histidine and glucose is presented in Fig. 3 as a function of heating time, temperature and water activity. The overall tendency towards development of antioxidative effect was similar to that of color development (Fig. 1). This might suggest that the formation of polymerized brown pigments is at least responsible for the development of antioxidative effect. Moreover, the reducing power of MRP increased rapidly for the period of initial $15 \mathrm{~min}$ at $100^{\circ} \mathrm{C}$ and $5 \mathrm{~min}$ at $120^{\circ} \mathrm{C}$ at any water activities tested, and plataued out thereafter (data not shown). The development of reducing power during the initial stage of the Maillard reaction 


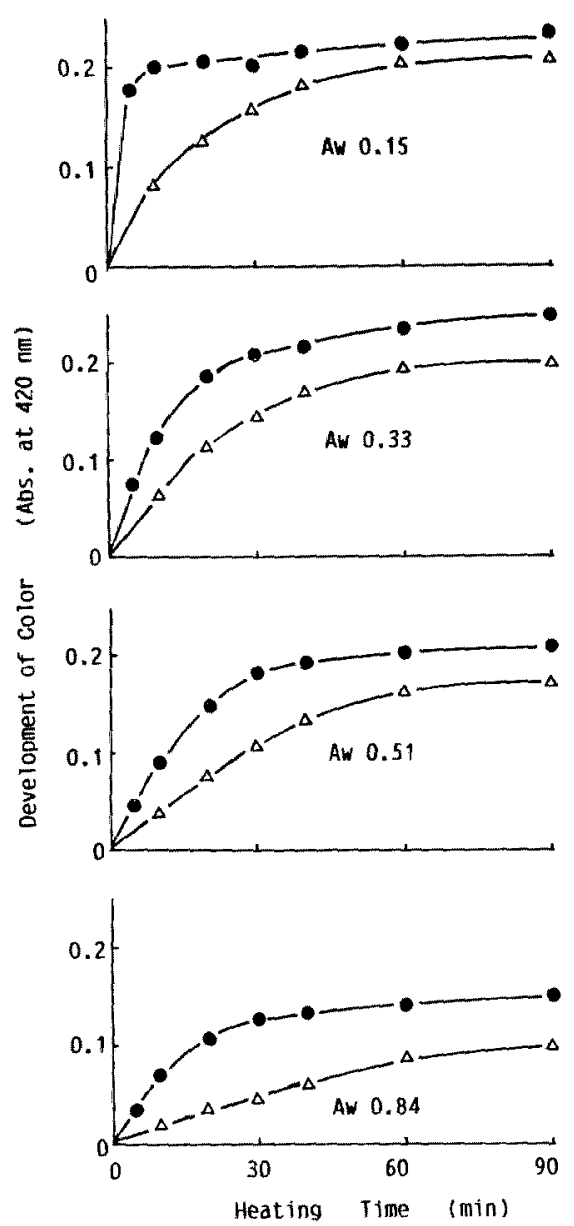

Fig. 3. Development of antioxidative effect during the Maillard reaction between histidine and glucose (molar ratio $1: 1)$ at $\mathrm{pH} 9$.

$\Delta: 100^{\circ} \mathrm{C}$ heating, $\bullet: 120^{\circ} \mathrm{C}$ heating.

might contribute to the development of antioxidative effect under the conditions used in this study.

Fig. 4 depicts the influence of water activity of the model system on the initial rate of antioxidative effect development. It is clear that this also increases with decrease in water activity, particularly for $\mathrm{Aw}<0.5$ at $120^{\circ} \mathrm{C}$. Considering this together with results for the rate of color development (Fig. 2), it appears that the activation energy for the development of antioxidative effect is larger than that for the color development particularly at the lower water activity region.

\section{Addition of MRP to Kamaboko-type Sardine Pro- duct}

From the results obtained above, the optimum condition for the development of antioxidative

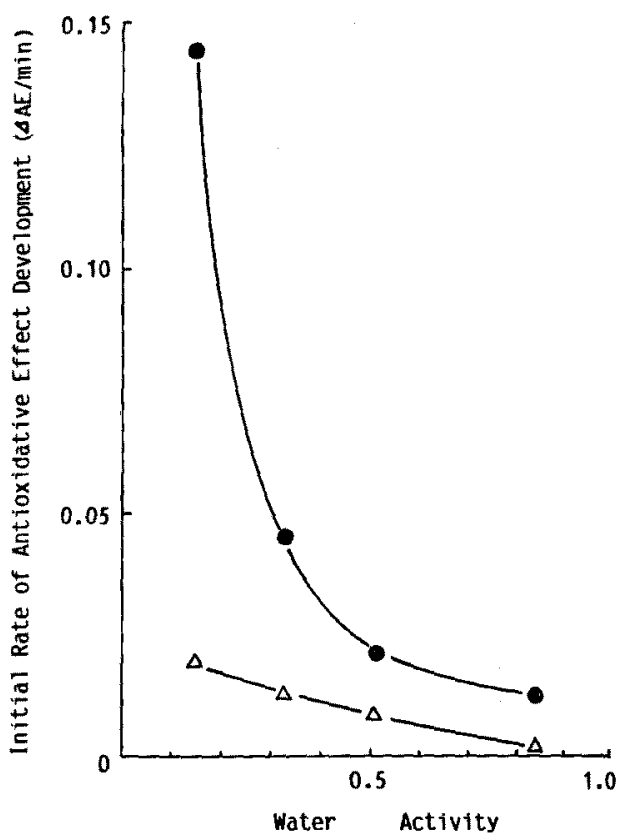

Fig. 4. Relationship between water activity and the initial rate of antioxidative effect development as measured by the oxygen electrode method. $\triangle: 100^{\circ} \mathrm{C}$ heating, $\bullet: 120^{\circ} \mathrm{C}$ heating.

effect in this study was as follow; Aw $0.15,40 \mathrm{~min}$ heating at $120^{\circ} \mathrm{C}$. In the next experiments, antioxidative effect towards fish lipids was examined by incorporating this optimum system to kamaboho-type sardine product. Despite some applications of antioxidative MRP for cookies, ${ }^{\text {? }}$ cereals, ${ }^{14)}$ and sausage, ${ }^{8)}$ little work has been carried out on the use of MRP for fish meat products which are rich in polyunsaturated fatty acids. ${ }^{18,18)}$

Fig. 5 illustrates the development of POV in sardine lipids extracted from kamaboko-type product during the storage at $4^{\circ} \mathrm{C}$. It is obvious that lipid oxidation was effectively retarded with the addition of MRP, especially at levels of 2 and $3 \%$. BHA $(0.095 \%)$ also inhibited the oxidation of sardine lipids and its effectiveness was close to that of MRP at the level of $2.0 \%$. Effect of ascorbic acid $(0.095 \%)$ was poorer than that of BHA, but was superior to that of MRP $(0.5 \%)$. Rancid odor of kamaboko-type sardine product became apparent when POV of the product was larger than $30 \mathrm{meq} / \mathrm{kg}$. POV reached $30 \mathrm{meq} / \mathrm{kg}$ within 3-4 days for the control, 9 days at $0.5 \%$ MRP, and 11 days at $1 \% \mathrm{MRP}$, indicating that the shelf-life of kamaboko-type product increased significantly with the addition of MRP even below 


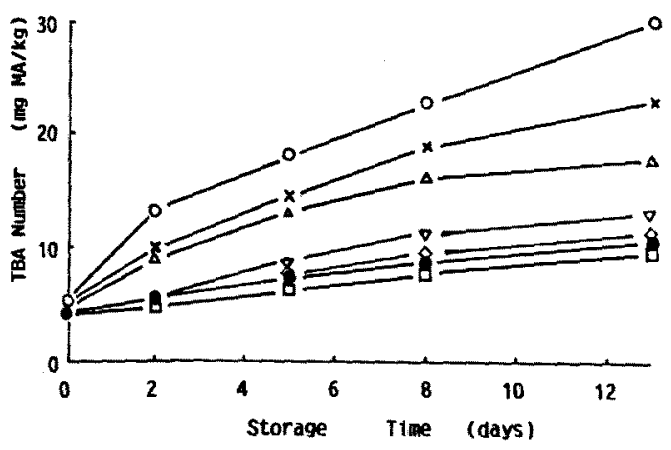

Fig. 5. Changes in POV in kamaboko-type sardine product containing $0-3 \%$ Maillard reaction products during the storage at $4^{\circ} \mathrm{C}$.

$O:$ Control, $x: 0.5 \%, \triangle: 1.0 \%, 0: 2.0 \%, \square:$ $3.0 \%, \diamond:$ BHA $(0.095 \%), \nabla:$ L-ascorbic acid $(0.095 \%)$.

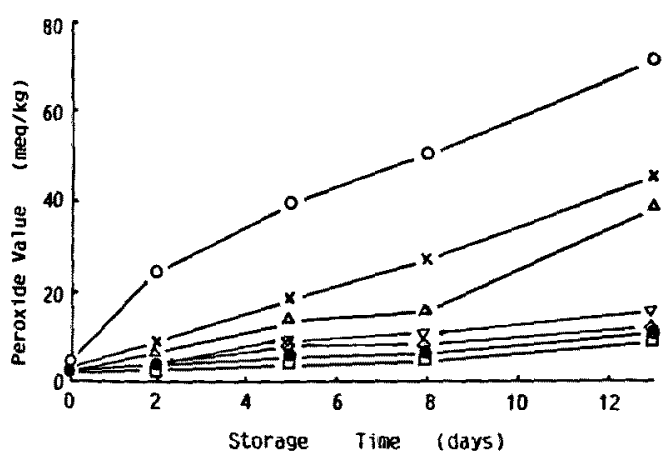

Fig. 6. Changes in TBA number in kamaboko-type sardine product containing $0-3 \%$ Maillard reaction products during the storage at $4{ }^{\circ} \mathrm{C}$.

$O:$ Control, $x: 0.5 \%, \triangle: 1.0 \%, \bullet: 2.0 \%, \square:$ $3.0 \%, \diamond:$ BHA $(0.095 \%), \nabla:$ Lascorbic acid $(0.095 \%)$.

$1 \%$. Moreover, the addition of $2-3 \%$ MRP almost completely inhibited the oxidation of sardine lipids over 13 days.

The effect of storage time on TBA number of kamaboho-type sardine product is shown in Fig. 6. The overall pattern of TBA number increase is similar to that of POV. In particular, the use of MRP at levels of 2-3\% considerably retarded the development of rancidity over 13 days. From Figs. 5 and 6, it was concluded that MRP prepared in this study from histidine and glucose was very effective for the prevention of lipid oxidation in kamaboho-type sardine product during the storage. The addition of MRP at levels of $1-3 \%$ seems to be too great as a food additive. However, the actual weight of MRP is approximately one sixth of the weight of prepartion used here,
Table 1. Tristimulus color values of kamaboko-type sardine product containing $0-3 \% \mathrm{MRP}^{*}$

\begin{tabular}{lrrrrr}
\hline \multicolumn{5}{c}{ Percentage of MRP Added } \\
\cline { 2 - 6 } & \multicolumn{1}{c}{0} & 0.5 & 1.0 & 2.0 & \multicolumn{1}{c}{3.0} \\
\hline L & 52.5 & 50.0 & 48.5 & 45.3 & 43.3 \\
a & 0.3 & 1.1 & 2.5 & 3.0 & 4.3 \\
b & 9.3 & 11.2 & 13.4 & 14.1 & 15.1 \\
\hline * MRP: Maillared reaction products prepared by heating his- \\
tidine and glucose (molar ratio 1: 1) in the presence of \\
microcrystalline cellulose powder at $120^{\circ} \mathrm{C}$ for 40 min \\
and Aw 0.15.
\end{tabular}

since the remainder was crystalline cellulose powder, which is intert to the Maillard reation, as adsorbant.

Since antioxidative effect of MRP from histidine and glucose was evaluated from the degree of autoxidation of linoleic acid in this study (Fig. 3 ), it is not clear whether antioxidative MRP prepared are also effective towards other fatty acids such as EPA and DHA, which are dominant in sardine lipids and more prone to autoxidation than linoleic acid. However, it can be concluded that MRP prepared in this study effectively prevent the oxidation of such fatty acids, because the development of both POV and TBA of sardine lipids was retarded significantly by the addition of MRP.

Although the texture, taste and flavor of kamaboko-type sardine product were not altered by the addition of MRP, the color of the product varied with the level of MRP added. Table 1 shows the changes in color of the product prior to the storage. Kamaboko-type sardine product became less white ( $L$ value increased), more red (a value increased) and more yellow (b value increased) with the increasing amount of MRP. However, the color of products did not change during the storage at $4^{\circ} \mathrm{C}$. From this point, the preparation or separation of colorless antioxidative MRP has been under way in our laboratory.

\section{References}

1) E. R. Stadtman: Adv, in Food Res., 1, 325-372 (1948).

2) T. M. Reynolds: Adv. in Food Res., 12, 1-52 (1963).

3) T. M. Reynolds: Adv. in Food Res., 14, 167283 (1965).

4) M. Namiki: Adv. in Food Res., 32, 115-184 (1988).

5) N. Yamaguchi: J. Japan Oil Chem. Soc., 18, 111-117 (1969). 
6) H. Kato: J. Food Hyg. Soc. Japan, 14, 343-351 (1973).

7) H. Lingnert: J. Food Process, Preserv., 4, 219233 (1980).

8) H. Lingnert and B. Lundgren: J. Food Process, Preserv., 4, 235-246 (1980).

9) D. C. Farr, J. Loliger, and M. C. Savoy: J. Sci. Food Agric., 37, 804-810 (1986).

10) A. O. A.C.: in "Official Methods of Analysis of A. O. A. C." (ed. by W. Horwitz), Washington, D. C., 1970 , pp. $445-446$.

11) R. O. Sinnhuber and T. C. Yu: Food Technol., 12, 9-12 (1958).
12) M. Tanaka, Y. Nagashima, and T. Taguchi: Nippon Suisan Gakkaishi, 52, 1251-1274 (1986).

13) H. C. Warmbier, R. A. Schnikels, and T.P. Labuza: J. Food Sci., 41, 528-531 (1976).

14) R. H. Anderson, D. H. Moran, T. E. Huntley, and J.L. Holahan: Food Technol, 17, 15871592 (1963).

15) R. Beckel, H. Lingnert, B. Lundgren, G. Hall, and G. R. Waller: J. Food Sci., 50, 501-502+ 530 (1985).

16) S.-Y. Cho, A. Miura, K. Fujimoto, and M. Inai: Nippon Suisan Gakkaishi, 54, 1017-1022 (1988). 